AGRICULTURE AND BIOLOGY JOURNAL OF NORTH AMERICA

ISSN Print: 2151-7517, ISSN Online: 2151-7525, doi:10.5251/abjna.2012.3.11.466.475

(C) 2012, ScienceHu $\beta$, http://www.scihub.org/ABJNA

\title{
RAPD analysis of genetic diversity in natural populations of Aegilops geniculata Roth and Triticum durum Desf from Tunisia
}

\author{
Asma Aloui Mahjoub ${ }^{1-3 *}$, Kaled Mguis ${ }^{1}$, Mustapha Rouaissi ${ }^{2}$, Raoudha Abdellaoui ${ }^{4}$ and \\ Nadia Ben Brahim ${ }^{1}$ \\ ${ }^{1}$ Laboratory of botanic of INRAT, Hedi Karray, 2049 Ariana, Tunisia \\ ${ }^{2}$ Laboratoire de biotechnologie et de physiologie végétale, Institut National de la Recherche \\ Agronomique de Tunisie, 2049, Rue Hédi Karray, Ariana, Tunisie \\ ${ }^{3}$ Genetic and bio-resources unit, University of Sciences of Tunis, Tunis, Tunisia \\ ${ }^{4}$ Arid Regions Institute of Medenine, Street Djerba 22.5 Km 4182 Medenine, Tunisia
}

\begin{abstract}
Aegilops geniculata Roth (Poaceae) is a potential source of genetic variation for wheat improvement. In order to distinguish and evaluate different genetic of Aegilops and Triticum using RAPD markers, thirteen Aegilops geniculata populations and three durum wheat varieties (Triticum durum Desf.) were collected from different regions of Tunisia (North and central). Aegilops geniculata Roth populations (Goussa, Djebel Abderahmen, Tabarka, Djebel Ressas), (Bizerte, Zaghouan), (Mekna, Ain Zana), (Djebel Oust, Souk jemaa, Sbeitla), (Djebel Serj, Nefza) constitute different groups. Complement gene locus were amplified by nineteen RAPD primers witch produced 212 bands, that 182 bands (about $86 \%$ ) were polymorphic. The results revealed that genetic diversity within populations was relatively high. Nei's genetic diversity $(H)$ and Shannon's index (I) were $0.324,0.484$ respectively. Global AMOVA showed that genetic variation within populations accounted $80 \%$ occurring $\left(\Phi_{\mathrm{PT}}=0.205 \mathrm{p}<0.05\right)$. The total genetic diversity $(\mathrm{Ht})$ and the within population genetic diversity (Hs) were 0.3195 and 0.1516 respectively, Total gene diversity was attributable mostly to diversity within population, indicating that the groups of populations were likely to differ genetically. Genetic differentiation was low in the two closely related species. The amount of gene flow $(\mathrm{Nm})$ among groups of populations was also low. Despite the relatively restricted geographical range covered by the investigation, studied groups of populations exhibited a pronounced genetic divergence at different hierarchical levels. Therefore, dendrogram based on Nei's genetic distance indicated segregation of Aegilops geniculata groups of populations and Triticum durum into two main clear pattern clusters. All this results proved that RAPD markers could be a powerful tool for investigating genetic variation and for detecting genetic structuring of populations at different hierarchical levels according to the segregation by distance model.
\end{abstract}

Keywords: Aegilops geniculata Roth., AMOVA., Triticum durum Desf., Genetic diversity, RAPD.

\section{INTRODUCTION}

The eroding genetic base of cultivated wheat, Rapid changes in climatic and environmental stress conditions have led workers to investigate the possibility of using the genetic diversity present in wild relatives of cultivated crops (Feldman and Sears 1981). Its have been sustaining under intensive stress conditions, by modifying themselves to adapt to newly emerging conditions (Nevo et al.., 2002). Great interest has been focused to the genus Aegilops L., which is closely related to Triticum constitutes a precious source of economically important traits for wheat improvement (Valkoun et al.., 1985; Holubec et al.., 1993) particularly those associated with disease resistance (Bouktila, 2001; Martin-Sanchez et al.., 2003) and other economically desirable attributes. (Wang et al.., 2000; Nevo et al.., 2002) stated that Aegilops germplasm should be considered an important source of variability for breeding genetic bases of cultivated crops.

Aegilops geniculata Roth. is an annual self-fertile plant (Hammer, 1980), allo-tetraploid species $(2 n=$ $4 \mathrm{X}=28$ ) with $\mathrm{MU}$ genomes Van Slageren (1994), belonging to tribe Triticeae Dumort, subtribe Triticinae Griseb. It has a wide distribution in Asia and around the Mediterranean Sea region, characterized by a dry summer season with high temperature and high irradiance. Three annual species of Aegilops were reported in Tunisia (Cuénod 
et al.., 1954): Ae. geniculata Roth, Ae. triuncialis L and Ae. ventricosa Taush. Aegilops geniculata Roth is widely distributed while the last two species are quite rare. Its geographical distribution would indicate a large distribution of climatic regions: cold and humid mountains, hot and dry valley. Habitats of Aegilops geniculata Roth in the Fertile Crescent differ widely in the humid areas receiving around $800 \mathrm{~mm}$ and the lower arid area with less than $150 \mathrm{~mm}$ (Ben Brahim et al.., 2002). Aegilops, is equally adapted to areas with altitude ranging from 10 to $900 \mathrm{~m}$.

A large number of methods are available for the assessment of genetic variability, diversity and relatedness among germplasm as well as for molecular fingerprinting. DNA based techniques represent reliable tools and obviate many of the standard problems associated with other techniques. They allow also a high throughput of material for DNA typing.

Molecular markers have been used to understand the genetics and genomic organization of local varieties, and have been great value for breeding purposes. Although the value of a diverse genetic base for the resistance of cereals to diseases has been advocated (Zhu et al.., 2000), future breeding programs also depend upon the availability of genetic variability to increase productivity. Hence, there is a need to develop cultivars with a diverse genetic base to achieve self-sufficiency and sustainability. Knowledge of diversity patterns will allow breeders to better understand the evolutionary relationships among populations (Sun et al.., 1998). Moreover, molecular markers have been especially used for studying the genetic diversity among a number of species of the tribe Triticeae (Charmers et al.., 2001;
Bai et al.., 2003; Sun et al.., 2003). In this context, RAPD markers have found application in many fields including assessment of genetic diversity, linkage mapping, systematics and estimations of population genetic parameters. Several authors have already demonstrated the usefulness of RAPD at specific level in the genus of Aegilops (Zaharieva et al.., 2001; Migdadi, 2006).

In order to assess, conserve and update the genetic diversity of Tunisian species (Aegilops geniculata Roth. and Triticum durum Desf.), we initiated a research program. It aims to investigate the local Aegilops geniculata populations from different sites, assess the genetic diversity of the two species and estimate their relationships and similarities in order to evaluate the potential of molecular markers in breeding programs as well as in germplasm conservation.

\section{MATERIAL AND METHODS}

Plant material and DNA extraction: Total DNA was extracted from young leaves of 13 Aegilops geniculata populations collected in North and Central Tunisia and 3 durum wheat varieties (Triticum durum Desf.) (Table 1). All species were planted and grown in the containers to the midtillering stage. Plant DNAs were extracted by the cetylmethylammoniumm bromide (CTAB) method with minor modification Murray and Thompson (1980). After purification, the DNA concentration was spectrophotometrically estimated. DNA integrity was assessed by $0.8 \%$ agarose gel electrophoresis (Sambrook et al.., 1989). The extracted DNA was diluted to $20 \mathrm{ng} / \mu \mathrm{l}$ and used for PCR amplifications.

Table 1. Aegilops geniculata populations and Triticum durum studied with their sites of origin in Tunisia

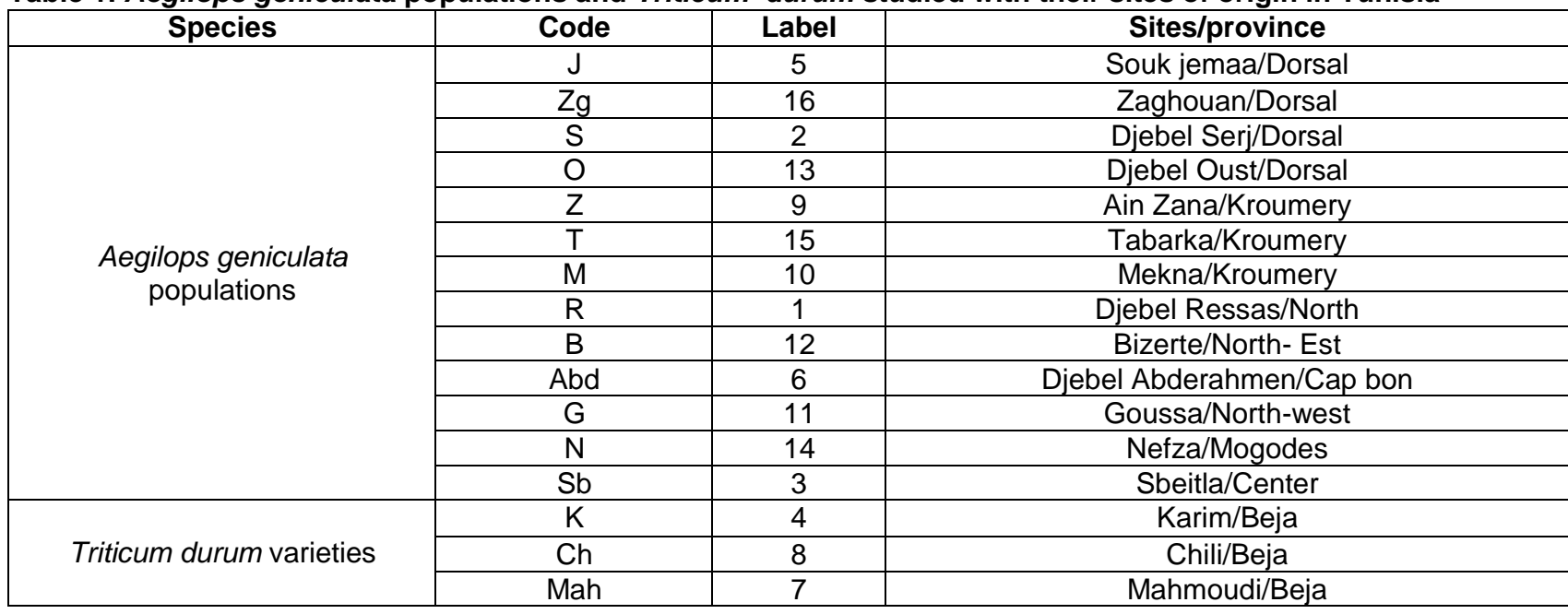


Polymerase chain reaction (PCR): Nineteen primers purchased from Operon Technologies inc. (Alameda, USA) were used for the amplification of random DNA sequences in this study (Table 2). PCR reactions were performed, in a $25 \mu$ l volume reaction mixture containing between 20-40 ng of total cellular DNA, $5 \mu \mathrm{l}$ of $5 \mathrm{x}$ Taq DNA polymerase buffer, $0.5 \mu \mathrm{l}$ dNTP $(200 \mu \mathrm{M}), 0.2 \mu$ Taq DNA polymerase $(5 \mathrm{U} / \mu \mathrm{l})$ et
$1 \mu \mathrm{L}$ de $\mathrm{MgCl}_{2}(2.5 \mathrm{mM}), 25 \mu \mathrm{M}$ of primer. The reaction mix was overlaid with a drop of mineral water. PCRs were performed using a Biometra UNO II thermal-cycler and involved an initial denaturation step ( $\left.94^{\circ} \mathrm{C}, 5 \mathrm{~min}\right), 40$ amplification cycles (each 94 ${ }^{\circ} \mathrm{C}, 30 \mathrm{~s} ; 38{ }^{\circ} \mathrm{C}, 1 \mathrm{~min}$ and $72{ }^{\circ} \mathrm{C}, 1 \mathrm{~min}$ ) and a final extension step $\left(72^{\circ} \mathrm{C}, 10 \mathrm{~min}\right)$.

Table 2. Nucleotide sequence of 19 primers with the number of amplified, polymorphic and percentages of polymorphic bans of Aegilops geniculata and Triticum durum.

\begin{tabular}{|c|c|c|c|c|c|}
\hline Primers & Sequences (5'-3') & $\begin{array}{c}\text { Molecular } \\
\text { weight } \\
\text { markers (MW) }\end{array}$ & $\begin{array}{c}\text { No. of RAPD } \\
\text { bands } \\
\text { generated }\end{array}$ & $\begin{array}{c}\text { No. Of } \\
\text { polymorphic } \\
\text { bands }\end{array}$ & $\begin{array}{c}\text { Polymorphism } \\
\text { (\%) }\end{array}$ \\
\hline OPM14 & AGGGTCGTTC & 3050 & 9 & 6 & 67 \\
\hline OPB13 & TTCCCCCGCT & 2906 & 12 & 9 & 75 \\
\hline OPJ18 & TGGTCGCAGA & 3059 & 11 & 7 & 64 \\
\hline OPG02 & GGCATGAGC & 3084 & 13 & 13 & 100 \\
\hline OPF10 & GGAAGCTTGG & 3099 & 12 & 11 & 92 \\
\hline OPD10 & GGTCTACACC & 2979 & 9 & 6 & 67 \\
\hline OPG10 & AGGGCCGTCT & 3035 & 11 & 10 & 91 \\
\hline OPG12 & CAGCTCACGA & 2988 & 14 & 14 & 100 \\
\hline OPM12 & GGGACGTTGG & 3115 & 9 & 9 & 100 \\
\hline OPA06 & GGTCCCTGAC & 2995 & 14 & 14 & 100 \\
\hline OPJ16 & CTGCTTAGGG & 3050 & 11 & 10 & 91 \\
\hline OPJ06 & TCGTTCCGCA & 2970 & 9 & 9 & 100 \\
\hline OPM16 & GTAACCAGCC & 2988 & 11 & 5 & 45 \\
\hline OPD20 & ACCCGGTCAC & 2964 & 11 & 9 & 82 \\
\hline OPD18 & GAGAGCCAAC & 3037 & 9 & 9 & 100 \\
\hline OPE14 & TGCGGCTGAG & 3075 & 14 & 14 & 100 \\
\hline OPA12 & TCGGCGATAG & 3059 & 9 & 9 & 100 \\
\hline OPB05 & TGCGCCCTTC & 2946 & 13 & 10 & 77 \\
\hline OPJ04 & CCGAACACGG & 3013 & 11 & 8 & 73 \\
\hline Total & & & 212 & 182 & 86 \\
\hline
\end{tabular}

Agarose gel electrophoresis: In order to test reproducibility of the results, One PCR amplification was performed for each sample. Amplification products were analysed using $1 \times$ Tris-Acetate- EDTA buffer (TAE) and loaded onto $2 \%$ agarose gels stained with ethidium bromide. Electrophoresis was carried out and RAPD fragments were photographed under UV light.

Data analysis: As demonstrated in previous research work (Mahjoub et al.., 2008), (Goussa, Djebel Abderahmen, Tabarka, Djebel Ressas), (Bizerte, Zaghouan), (Mekna, Ain Zana), (Djebel Oust, Souk jemaa, Sbeitla), (Djebel Serj, Nefza) populations constitute different groups of Aegilops geniculata Roth according to agromorphological behaviour. In this study, we will analysis the genetic diversity, usually called heterozygosity of Aegilops geniculata and Triticum durum groups and theirs structures. RAPD bands were scored for their presence (1) or absence (0) and then transformed into a binary matrix. Each marker band was assumed to represent a single locus.

The level of genetic diversity: PPL, AL, PL, Ne, Na, $\mathrm{H}$, I, Gst, Nm and Nei's genetic distance were calculated. The dendrogram separating population groups was constructed using UPGMA method based on matrix distance. All these calculations were performed by using POPGENE 32 program ver. 1.32 (Yeh et al.., 1999). Analysis of Molecular Variance (AMOVA) procedure was used as described in Excoffier et al.. (1992). This analysis was performed with GenAIEx V6.1 (Peakall and Smouse, 2006).

\section{RESULTS}

Genetic diversity: The data for RAPD analysis were scored from photographs of the ethidium bromide stained agarose gels. Analysis of the amplification patterns of Aegilops geniculata groups of populations and Triticum durum showed a difference by position and number of generated bands. The nineteen primers chosen for analysis were assumed to be a 
random sample of the genome and generated a total of 212 bands ranging from 9 with (OPM14, OPD10, OPM12, OPJ06, OPD18, OPA12) to 14 with (OPG12, OPA06, OPE14), an average of 9.57 bans per primers that ranged in size from 0.5 to $3 \mathrm{~Kb}$. The patterns of RAPD bans produced by the primer OPB05 is shown in figure 1 as exemple. Of the 212 bands, $86 \%$ (182 in total) were polymorphic (Table 2).

At the groups of population level, the percentage of polymorphic loci (PPL) ranged from $26.89 \%$ to $55.19 \%$, with an average of $38.06 \%$ (Table 3 ). The Ae.pop ${ }_{1}$ had the highest value of polymorphism while the Ae.pop 4 had the smallest, but this value in Tri.pop $_{6}$ is $40.09 \%$. The average of amplified loci (AL) was $314.83 ; 80.66$ of them were polymorphic. The observed number of alleles $(\mathrm{Na})$ in the six groups of populations varied from 1.269 to 1.551 , with an average of 1.896 . The effective number of alleles $(\mathrm{Ne})$ ranged from 1.190 to 1.386 , with an average of 1.551. The average Nei's unbiased genetic diversity (H) was estimated to be 0.324 at the groups of population level (from 0.111 to 0.217). The Shannon's indices (I) was estimated to be 0.484 (from 0.163 to 0.318 ) with SD of 0.2075 .

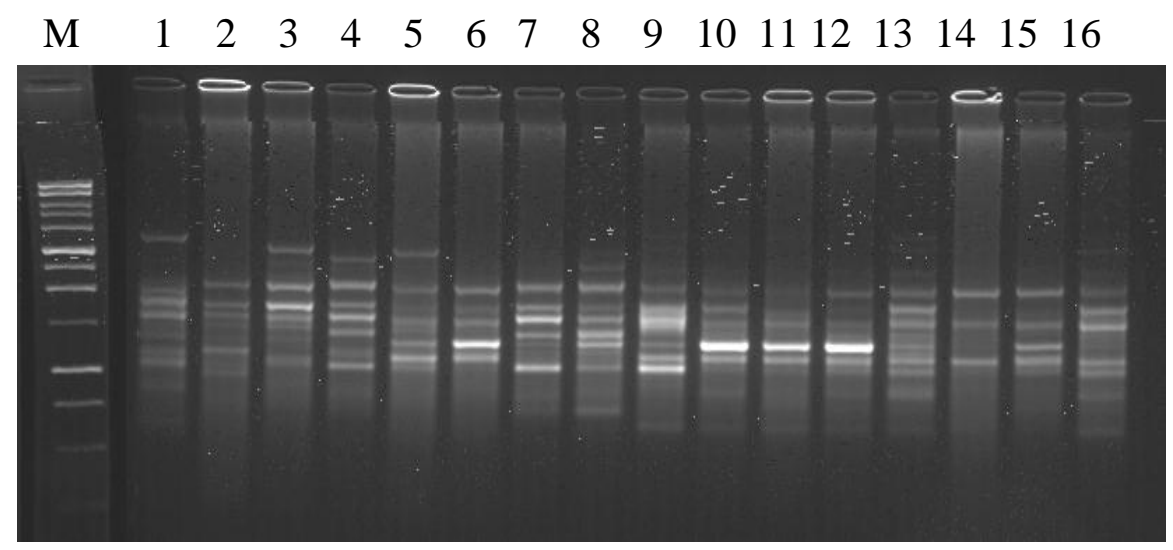

Fig. 1. Amplification profile of 13 Aegilops geniculata populations and 3 durum wheat varieties with OPB05 primer.

Lane 1= Djebel Ressas, Lane 2= Djebel Serj, Lane 3= Sbeitla, Lane 4= Karim, Lane 5= Souk jemaa, Lane $6=$ Djebel Abderahmen, Lane 7= Mahmoudi, Lane 8= Chili, Lane 9= Ain Zana, Lane 10= Mekna, Lane 11= Goussa, Lane 12=Bizerte, Lane 13= Djebel Oust, Lane 14=Nefza, Lane 15=Tabarka, Lane 16=Zaghouan, $M=$ Molecular weight markers: $1 \mathrm{~Kb}$ DNA Ladder 
Table 3. Genetic Diversity indices of Aegilops geniculata groups of populations and Triticum durum

\begin{tabular}{|c|c|c|c|c|c|c|c|c|}
\hline Pop grp code & $\begin{array}{c}\text { Simpe } \\
\text { Size }\end{array}$ & $\mathrm{Na}$ & $\mathrm{Ne}$ & I & $\mathbf{H}$ & $\overline{A L}$ & PPL & PL \\
\hline$A e$ pop $_{1}$ & 4 & $1.551(0.498)$ & $1.386(0.407)$ & $0.318(0.301)$ & $0.217(0.212)$ & 329 & 55.19 & 117 \\
\hline$A e$ pop $_{2}$ & 2 & $1.302(0.460)$ & $1.213(0.325)$ & $0.182(0.278)$ & $0.125(0.190)$ & 276 & 30.19 & 64 \\
\hline$A e$ pop $_{3}$ & 3 & $1.443(0.498)$ & $1.284(0.362)$ & $0.248(0.286)$ & $0.167(0.197)$ & 306 & 44.34 & 94 \\
\hline$A e$ pop $_{4}$ & 2 & $1.269(0.444)$ & $1.190(0.314)$ & $0.163(0.269)$ & $0.111(0.184)$ & 402 & 26.89 & 57 \\
\hline Ae pop $_{5}$ & 2 & $1.316(0.466)$ & $1.224(0.329)$ & $0.191(0.282)$ & $0.131(0.193)$ & 279 & 31.60 & 67 \\
\hline Tri pop 6 & 3 & $1.401(0.491)$ & $1.278(0.379)$ & $0.233(0.292)$ & $0.158(0.203)$ & 297 & 40.09 & 85 \\
\hline Average & & 1.896 & 1.551 & 0.484 & 0.324 & 314.83 & 38.05 & $\begin{array}{r}80 . \\
66\end{array}$ \\
\hline $\begin{array}{c}\text { St. deviation } \\
\text { (SD) }\end{array}$ & & 0.306 & 0.322 & 0.2075 & 0.155 & & & \\
\hline
\end{tabular}

Na: Observed number of alleles, Ne: Effective number of alleles, I: Shannon's Diversity Index, H: Nei's genetic diversity index, AL: Amplified loci, PPL: \% Polymorphic loci, PL: Polymorphic loci

Genetic diversity indexes of Nei have been estimated for all groups of populations (Table 4). The total genetic diversity $\left(\mathrm{H}_{\mathrm{T}}\right)$ and the intra-population genetic diversity $\left(\mathrm{H}_{\mathrm{S}}\right)$ are respectively 0.3195 and 0.1516 . The $M_{14}$ and $M_{16}$ locus showed the lowest $\left(H_{S}\right)$ values $(0.0787,0.0732)$ but $J_{18}$ and $M_{16}$ locus indicated the lowest $\left(\mathrm{H}_{\mathrm{T}}\right)$ values $(0.2166,0.1651)$. As expected, total genetic diversity $\left(\mathrm{H}_{\mathrm{T}}\right)$ was upper estimated compared with $\left(\mathrm{H}_{\mathrm{S}}\right)$. Therefore, the genetic diversity values for each locus were very considerable and levels of inter-population genetic diversity were close. Across all RAPD markers the Gst value was 0.5255 , indicating that about $52.50 \%$ of the total genetic variation could be explained by RAPDs differences while the remaining $47.5 \%$ might be attributable to differences among groups of populations. These results indicate that genetic differentiation was low in the two closely related species (Aegilops geniculata populations and Triticum durum).

Table 4. Estimated Nei's diversity in Aegilops geniculata groups of population and Triticum durum based on RAPD markers

\begin{tabular}{|c|c|c|c|c|c|}
\hline Locus & Simple Size & $\mathrm{Ht}$ & Hs & Gst & $\mathrm{Nm}$ \\
\hline M14 & 16 & 0,2312 & 0,0787 & 0,4255 & 0,3070 \\
\hline B13 & 16 & 0,2301 & 0,1143 & 0,3797 & 0,4267 \\
\hline $\mathrm{J} 18$ & 16 & 0,2166 & 0,1142 & 0,4526 & 0,4567 \\
\hline G02 & 16 & 0,4004 & 0,1804 & 0,5072 & 0,4063 \\
\hline $\mathrm{F} 10$ & 16 & 0,3682 & 0,1988 & 0,4414 & 1,4353 \\
\hline D10 & 16 & 0,2419 & 0,1191 & 0,3096 & 0,2208 \\
\hline G10 & 16 & 0,3407 & 0,1628 & 0,5078 & 0,3694 \\
\hline G12 & 16 & 0,3592 & 0,1877 & 0,4148 & 0,3527 \\
\hline M12 & 16 & 0,4221 & 0,2183 & 0,4659 & 0,5369 \\
\hline A06 & 16 & 0,3778 & 0,2212 & 0,3836 & 0,4790 \\
\hline J16 & 16 & 0,2797 & 0,1693 & 0,3395 & 0,4990 \\
\hline J06 & 16 & 0,4286 & 0,1785 & 0,5523 & 0,3838 \\
\hline M16 & 16 & 0,1651 & 0,0732 & 0,2810 & 0,1802 \\
\hline D20 & 16 & 0,3403 & 0,1244 & 0,5447 & 0,3579 \\
\hline D18 & 16 & 0,3885 & 0,1398 & 0,5448 & 0,2719 \\
\hline E14 & 16 & 0,3317 & 0,1582 & 0,4020 & 0,3082 \\
\hline A12 & 16 & 0,3752 & 0,1597 & 0,5531 & 0,2891 \\
\hline B05 & 16 & 0,3184 & 0,1381 & 0,5216 & 0,3730 \\
\hline J04 & 16 & 0,2444 & 0,1062 & 0,5317 & 0,2657 \\
\hline Mean & 16 & 0.3195 & 0.1516 & 0.5255 & 0.4515 \\
\hline St.deviation (SD) & 16 & 0.0241 & 0.0106 & & \\
\hline
\end{tabular}

$\mathrm{H}_{\mathrm{S}}$ : Genetic diversity within population (intra-population GD); $\mathrm{H}_{\mathrm{T}}$ : Total genetic diversity;

$\mathrm{G}_{\mathrm{ST}}$ : Coefficient of population differentiation (inter-population GD);

$\mathrm{N}_{\mathrm{m}}$ : Estimate of gene flow $\mathrm{N}_{\mathrm{m}}=0.5(1-\mathrm{Gst}) / \mathrm{Gst}$ 
The number of migrants per generation $(\mathrm{Nm})$ is an estimated value from Gst to measure the gene flow, the higher its value, the less genetic differentiation among populations. According to the previous study and estimation of gene flow (Wright, 1931), if $\mathrm{Nm}>1$, it can prevent the differentiation among populations caused by genetic drift. And, if $\mathrm{Nm}<1$, local populations tend to differentiate. The amount of gene flow (Nm) among (Aegilops geniculata populations and Triticum durum) varied from 0.1802 in $M_{16}$ to 1.4353 in $F_{10}$, and was found to be $0.4515(<1$ ) (Table 4 ), indicating negligible gene flow between the six local groups of populations and showing that they tend to differentiate in over all locus.

AMOVA (Analysis of Molecular Variance) of RAPD data of (Aegilops geniculata populations and Triticum durum) indicated that the major proportion (80\%) of the total variation was found within populations. In contrast, $20 \%$ of the variation was come from among populations. Analogous to Wright's $F_{S T}$ is also the ФPT value, estimated with AMOVA; it amounted to $0.205(p<0.05)$, based on permutation across the full data set. This AMOVA showed significant genetic differences among groups of populations (Table 5).

Table 5. summary of AMOVA analysis for the six population groups of using 212 RAPD bands

\begin{tabular}{|c|c|c|c|c|c|}
\hline Source & df & SS & MS & Est.Var & $\%$ \\
\hline Among pops & 5 & 256.625 & 51.325 & 7.886 & $20 \%$ \\
\hline Within pops & 10 & 306.250 & 30.625 & 30.625 & $80 \%$ \\
\hline Total & 15 & 562.875 & & 38.511 & $100 \%$ \\
\hline Stat & Value & $\mathrm{P}($ rand >=data $)$ & \multicolumn{3}{|l}{} \\
\hline PhiPT & 0.205 & 0.007 & &
\end{tabular}

SS: sum of squares; MS: mean squares; Est. Var. : estimated variability; \% : proportion of genetic variability; $\mathrm{p}$ : significance level

Genetic distance and genetic identity: Genetic identity and genetic distance were calculated for the groups of populations using unbiased measure of genetic identity and genetic distance (Nei, 1978). We observed that identity between Aegilops geniculata groups of populations and Triticum durum were variable, ranging from 0.5898 to 0.8849 (Table 6). Comparatively the higher genetic identity was found between Ae.pop 4 , Ae.pop $1(0.8849)$ and the lowest was observed between Ae.pop 2 , Tri.pop 6 (0.5898).
Within Aegilops geniculata groups of populations, the genetic distance was limited, as indicated by the high intra- populations similarity that ranged from 0.1223 to 0.2677 . In addition, Triticum durum exhibited a low level of intra-specific variation. The intra-specific similarity varied from 0.3949 to 0.5279 . It was observed by a low of $52.79 \%$ for the two closely related species (Aegilops geniculata populations and Triticum durum).

Table 6 . Nei's genetic identity (above diagonal) and genetic distance (below diagonal) among Aegilops geniculata groups of populations and Triticum durum

\begin{tabular}{|c|c|c|c|c|c|c|}
\hline & Ae pop1 & Ae pop2 & Ae pop3 & Ae pop4 & Ae pop5 & Tri pop6 \\
\hline Ae pop1 & 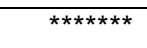 & 0.8448 & 0.8706 & 0.8849 & 0.8373 & 0.6696 \\
\hline Ae pop2 & 0.1687 & 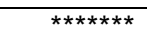 & 0.8179 & 0.7827 & 0.7652 & 0.5898 \\
\hline Ae pop3 & 0.1386 & 0.2010 & 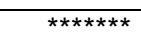 & 0.8490 & 0.8156 & 0.6738 \\
\hline Ae pop4 & 0.1223 & 0.2449 & 0.1637 & $* * * * * *$ & 0.8228 & 0.6112 \\
\hline Ae pop5 & 0.1776 & 0.2677 & 0.2038 & 0.1950 & 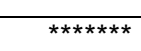 & 0.6164 \\
\hline Tri pop6 & 0.4011 & 0.5279 & 0.3949 & 0.4923 & 0.4839 & 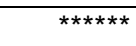 \\
\hline
\end{tabular}

The genetic structure: Dendrogram based on Nei's (1978) genetic distance using Unweighted Pair Group Method of Arithmetic Means (UPGMA) indicated segregation of the six groups of populations into two main clusters. The first cluster A is formed by four sub-clusters constituted by the Aegilops geniculata groups of populations. The first sub-cluster is formed by Ae.pop 1 and Ae.pop 4 which is (Goussa, Djebel Abderahmen, Tabarka, Djebel Ressas) and (Djebel Oust, Souk jemaa, Sbeitla) populations, related by $12.23 \%$ of similarity. The second sub-cluster formed by $\mathrm{Ae.pop}_{3}$ (Mekna, Ain Zana), joined the first with $16.37 \%$ of similarity. The third sub-cluster is constituted by Ae. pop 5 (Djebel Serj, Nefza) populations with $19.50 \%$ similarity and the fourth 
sub-cluster joined the third by $26.77 \%$ similarity. The second cluster $\mathrm{B}$ is formed only by Triticum durum which is Tri.pop $_{6}$ (Figure 2).

\section{DISCUSSION}

Genetic diversity of endangered species has always enthused evolutionary and conservation biologists. The ability of a species to adapt to environmental changes depends greatly on the genetic diversity in the species (Neel and Ellstrand, 2003; Anand et al.., 2004). Narrowing of gene pool and reduced genetic diversity pose challenges in the selection pressure brought in by environmental changes. RAPD analyses produced enough polymorphic markers for estimation of population genetic parameters, meeting the critical number of dominant markers suggested for reliable estimation of population genetic parameters (Mohapatra et al.., 2009).

The high level of polymorphism (86\%) in Aegilops geniculata Roth and Triticum durum observed in this study corroborated with the results reported by Baghizadeh and Khosravi (2011) in Aegilops germplasm, and by Kadri et al. (2010) in local Tunisian barley, but it is a little less than that obtained by do Amaral Júnior et al.. (2011). High polymorphism revealed that RAPD could resolve genetic variation among crop germplasm, identification of cultivars and for estimating genetic relationship (Silva et al.., 2005a; 2005b). In this present study, RAPD markers revealed $55.19 \%$ of polymorphism loci in Ae.pop 1 and $40.09 \%$ in Tri.pop . This result suggested that the two species (Triticum and Aegilops) could be distinguished with the RAPD primers. The use of abundant and high polymorphic DNA markers eliminates the limitations associated with morphological and biochemical characterization, especially for closely related species (Asif et al.., 2005: Schulman, 2007).

Data for observed number of alleles and effective number of alleles, for all the six groups of populations were analysed using ninety RAPD markers and their respective values were found as $1.896 ; 1.551$. Our results was considerable and higher than found by Siahsar et al.. (2011) in 14 lines of primary Tritipyrum using PCR-based molecular markers, and its were in agreement with the results found by Gupta et al.., 2008. The groups of populations involved in this experiment showed a comparatively high level of genetic diversity. High genetic variation was presented in Ae.pop $1(\mathrm{H}=0.217, \mathrm{I}=0.318)$. This result is corroborated with the results reported by
Noormohammadi et al.. (2011) in cotton hybrid genotypes using ISSR and RAPD markers. While the Ae. pop $_{4}$ had the low genetic diversity $(\mathrm{H}=0.111, \mathrm{I}=$ $0.163)$ as well as the Tri.pop $6(H=0.158, I=0.233)$. This result was in agreement with the result found by Siahsar et al.. (2011). The high level of genetic variation found in this study may be due to diverse geographic structure and the climatic heterogeneity of Ae.pop 1 (sub humid climate) compared to Ae.pop (the upper semi arid climate). Geographically populations accumulate genetic differences as they adapt to different environment (Souframanien and Gopalakrishna, 2004). However, the genetic closeness among the population of each group can be explained by the high degree of commonness.

It is important to confirm the genetic structure of population to understand its biology characteristics and explore the evolutional process and mechanisms. The genetic structure of population is mainly reflected by genetic differentiation within and between populations. The coefficient of genetic differentiation (Gst) as the most commonly used index expressed by the genetic variation between population accounts for the proportion in the total variation among populations. In our study, $\left(\mathrm{H}_{\mathrm{t}}\right)$ was found to be 0.3195 and (Hs) was contributed $47.45 \%$, indicating that the genetic diversity between the groups of populations occupied the half of the total. Total gene diversity was attributable mostly to diversity within population, indicating that the groups were likely to differ genetically. In addition, the amount of genetic diversity present within population genetic diversity $(\mathrm{Hs})$ value equalling 0.1516 , which is not surprising since Aegilops and Triticum are a highly self-crossing plants. These results were also reported for other self-crossing Poaceae family plants. For example, 59\% RAPD and 64\% ISSR was found among 14 populations of Oryza granulate $(\mathrm{Wu}$ et al.., 2004).

In the present study, the genetic differentiation $\left(G_{S T}=0.5255\right)$ was reasonable and considerable than the levels of differentiation detected among wheatgrass of Thinopyrum junceum based on isozymes (Nieto-Lopez et al.., 2003) and among Titipyrum lines using PCR-based molecular (Siahsar et al.., 2011). Jensen et al.. (1990) classified the Thinopyrum junceum complex as predominantly selfpollinating, while findings of Nieto-Lopez et al.. (2003) led to new genetic classification (out crossing), and disagree with traditional taxonomy. 
Gene flow, the genetic counterpart of dispersal, is an important content for study the genetic structure of species, which may lead to the 'genetic rescue' of genetically eroded populations (Richards, 2000; Ingvarsson, 2001). The indirect estimate of gene flow $(\mathrm{Nm})$ between our groups of populations was low (0.4515), implying that genetic drift could be the dominant evolutionary factor that shapes the groups of populations structure of Aegilops geniculata and Triticum durum according to Wright (1931). With a very low migration rate, genetic drift could have effectively isolated and differentiated the groups of populations after a long period, consistent with the almost equal percentage of within and between the groups of populations genetic variation.

The AMOVA technique is used to compare the groups of populations and assess them for distinctiveness. The groups of populations proved to be different at a probability level of $5 \%$. The among groups of populations variation accounted for $20 \%$ of the variation. AMOVA indicated that Aegilops geniculata populations and Triticum durum preserved the vast majority of their genetic variability within the groups of populations. This result was in accordance with the result found by Ehtemam et al.. (2009) in Triticum species. Shibing et al.. (2010) found that within population accounted for $78.3 \%$ of the total variation in Meconopsis quintuplinervia (Papaveraceae). In addition, this result suggests the existence of a reproduction model without inbreeding. The genetic variability within populations is a very important measure of species adaptation to environmental changes and of species survival (Sofia, 2006).

High degree of diversity of species belonging to Aegilops may be attributable to the fact that Aegilops is the wild relative of wheat. RAPD and other discontinuous markers can serve as a means of genetic distances to establish phylogenetic relationships (Rabey et al.., 2002). Estimation of genetic differences and discrimination of genetic relationship between the two species are for utilization of plant genetic resources. In the present study, dendrogram indicated segregation of Aegilops geniculata and Triticum durum groups of populations into two main clear pattern clusters (Figure. 2). Despite the relatively restricted geographical range covered by the investigation, the groups of populations studied exhibited a pronounced genetic divergence at different hierarchical levels. Kellogg and Mason-Gamer (1996) expressed their opinion that Aegilops and Triticum should be retained as two distinct genera. An inter-specific similarity was observed by a low genetic distance $(50 \%, 52 \%)$ for the two closely related species. This result reflects the fact that they have divergence in their genetic characteristics, while hybridisation between them for wheat improvement has brought the two species closer genetically (Martin- Sanchez et al.., 2003; Li et al.., 2004).

Since the cultivated wheat has a very narrow genetic diversity, for crop improvement, we always need to investigate the traits hidden in the wild types or the ancestors of the wheat, so that we can maintain the sustainable agriculture to feed ever increasing human population. Thus, by continual diversity assessment in nature, we can maintain the most diverse species in gene banks for conservation and crop improvement purposes. In this study, we prefer to perform analysis using RAPD marker system because it is one of the most highly polymorphic, reproducible. It could be a powerful tool for investigating genetic variation of Aegilops geniculata and Triticum durum, and for detecting genetic structuring of populations at different hierarchical levels according to the segregation by distance model. In this case, we believe that the data presented here will be a tool for other wheat researchers.

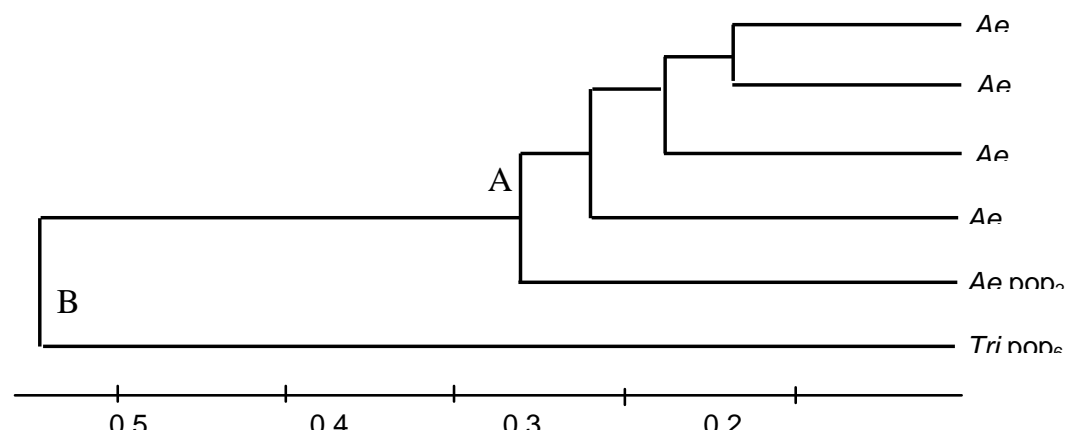

Fig. 2. UPGMA dendrogram based on Nei's (1978) genetic distance summarizing the data on differentiation between Aegilops geniculata groups of populations and Triticum durum according to RAPD analysis 


\section{CONCLUSION:}

Since the cultivated wheat has a very narrow genetic diversity, for crop improvement, we always need to investigate the traits hidden in the wild types or the ancestors of the wheat, so that we can maintain the sustainable agriculture to feed ever increasing human population. Thus, by continual diversity assessment in nature, we can maintain the most diverse species in gene banks for conservation and crop improvement purposes. In this study, we prefer to perform analysis using RAPD marker system because it is one of the most highly polymorphic, reproducible. It could be a powerful tool for investigating genetic variation of Aegilops geniculata and Triticum durum, and for detecting genetic structuring of populations at different hierarchical levels according to the segregation by distance model. In this case, we believe that the data presented here will be a tool for other wheat researchers.

\section{REFERENCES}

Anand, A., Rao, C.S., Eganathan, P., Kumar, N.A. and Swaminathan, M.S. (2004). Saving an endangered Taxon: Syzygium travancoricum Gamble: A case study focussing on its genetic diversity, and reintroduction. Physiol. Mol. Bio. Plants. 10: 233-242.

Asif, M., Rahman, M. and Zafar, Y. (2005). DNA fingerprinting studies of some wheat (Triticum aestivum L.) genotypes using random amplified polymorphic DNA (RAPD) analysis. Pak. J. Bot. 37(2): 271-277.

Baghizadeh, A and Khosravi, S. (2011). Genetic diversity assessment of Aegilops germplasm by RAPD molecular markers. Agric. Biol. J. N. Am. 2(2) : 197202

Ben Brahim, N., Sebei, H and El Gharbi, M.S., (2002). Collecte des populations d'Aegilops ovata et évaluation de la diversité génétique pour l'amélioration du blé. $13^{\text {èmes }}$ journées Biologiques. 20 -23, Mars 2002, Hammamet, Tunisie.

Bouktila, D. (2001). Etude du comportement des céréales Tunisiennes et Américaines vis à vis des Cécidomyies Tunisiennes (Diptères, Cecidomyidae). Mémoire de Diplôme D'études Approfondies en génétique et Biologie moléculaire: Université de Tunis El Manar, Faculté Des Sciences de Tunis.

Cuénod, A., Pottier-Alapetite, G., et Labbe, A. (1954). La flore analytique et synoptique de la Tunisie. Cryptogames vasculaires, gymnospermes et monocotylédones. Office de l'Exp. et de la Vulg. agricole de Tunisie - SEFAN Tunis, pp 287

Do Amaral Júnior, A.T., de Oliveira, É.C., Gonçalves Leandro, S.A., Scapim, C.A., Candido Liliam, S., Da Conceição, S.T.R., Vittorazzi, C. and Da Cunha, K.S. (2011). Assessment of genetic diversity among maize accessions using inter simple sequence repeats (ISSR) markers. African Journal of Biotechnology 10 (69): 15462-15469.

Ehtemam, M.H., Rahiminejad, M.R., Saeidi, H., Sayed Tabatabaei, B.E., Krattinger, S., Keller, B. (2009). The relationships among the $A$ genome bearing Triticum species as evidenced by SSRs in Iran. Wheat Inf. Serv. 108: pp33

Excoffier, L., Smouse, P.E. and Quattro, J.M. (1992). Analysis of molecular variance inferred from metric distances among DNA haplotypes: application to human mitochondrial DNA restriction data. Genetics 131: 479-491.

Gupta, S., Srivastava, M., Mishra, G.P., Naik, P.K., Chauhan, R.S., Tiwari, S.K., Meetul, K. and Raghwendra, S. (2008). Analogy of ISSR and RAPD markers for comparative analysis of genetic diversity among different Jatropha curcas genotypes. African Journal of Biotechnology 7(23): 4230-4243

Hammer,K.,(1980). Vorarbeiten zur monographischen Darstellung von Wildpflanzensortimenten: Aegilops L. Kulturpflanze 28: 33-180.

Ingvarsson, P.K. (2001). Restoration of genetic variation lost-the genetic rescue hypothesis. Trends Ecol. Evol. 16: $62-63$.

Jensen, K.B., Zhang, Y.F., and Deway, D.R. (1990). Mode of population of perennial species of Triticeae in relation to gnomically defined genera. Can. J. Plant Sci. 70: 215-225.

Kadri, K., Abdellawi, R., Cheikh-Mhamed, H., Ben-Naceur, M. and Trifi, M. (2010). Analysis of Genetic diversity and relationships in local Tunisian barley by RAPD and SSR analysis. African Journal of Biotechnology 9(44): 7429-7436

Kellogg, E.A.R. and Mason-Gamer, A.R.J. (1996). When genes tell different stories: the diploid genera of Triticeae (Gramineae). Systematic Botany 2: 11-17.

Li, H.J., Conner, R.L., Chen, O., Li, H.Y., Laroche, A., Graf, R.J. and Kuzyk, A.D. (2004). The transfer and characterization of resistance to common root rot from Thinopyrum ponticum to wheat. Genome 47: 215-223.

Mahjoub, A., Rouaissi, M., Mguis, K., El Gharbi, M.S., El Gazzah, M. and Ben Brahim, N. (2008). Agromorphological Variation in Spontaneous Aegilops geniculata Roth. Populations Suitable for Mediterranean Conditions. World Journal of Agricultural Sciences 4 (6): 737-744.

Martin-Sanchez, J.A., Gomez-Colmenarejo, M., Del Moral, J., Sin, E., Montes, M.J., Gonzalez-Belinchon, C., Lopez-Brana, I. and Delibes, A. (2003). A new Hessian fly resistance gene (H30) transferred from the wild grass Aegilops triuncialis to hexaploid wheat. Theor. Appl. Genet. 106: 1248-1255. 
Migdadi, H.M., Tell, A.M. and Masoud, S. (2006). Genetic diversity in some Aegilops species in Jordan revealed using RAPD. PGRNewsletter 139: 47-52

Mohapatra, K.P, Sehgal, R.N., Sharma, R.K. and Mohapatra, T. (2009). Genetic analysis and conservation of endangered medicinal tree species Taxus wallichiana in the Himalayan region. New Forests 37: 109-121.

Murray, M.G. and Thompson, W.F. (1980). Rapid isolation of high molecular weight plant DNA. Nucleic Acid Research 8: 4321-4325.

Neel, M.C. and Ellstrand, N.C. (2003). Conservation of genetic diversity in the endangered plant Eriogonum ovalifolium var. vineum. Conservation Genetics 4: 337352.

Nei, M. (1978). Estimation of average heterozygosity and genetic distance from a small number of individuals. Genetics 89: 583-590.

Nieto-Lopez, R.M., Soler, C., Garcia, P. (2003). Genetic diversity in wild Spanish populations of Thinopyrum junceum and Thinopyrum junceiforme using endosperm proteins and PCR-based markers. Hereditas 139: 18-27

Noormohammadi, Z., Shamee, M.H., Sheidai, M., Alishah, O. (2011). The comparison of inter simple sequence repeat and randomly amplified polymorphic DNA markers for genetic assessment of intra-specific cotton hybrid genotypes. Gene conserve 42: $270-292$

Peakall, R. and Smouse, P.E. (2006). GENALEX 6: Genetic analysis in Excel. Population genetic software for teaching and research. Mol. Ecol. Nat. 6: 288-295.

Rabey, H.A, Badr, A., Schafer, P.R., Salamini, W.M. (2002). Speciation and species separation in Hordeum L. (Poaceae) resolved by discontinuous markers. Plant Biol. 4: 1-9

Richards, C.M. (2000). Inbreeding depression and genetic rescue in a plant metapopulation. Am. Nat. 155: 383394.

Sambrook, J., Fritish, E.F., Maniatis, T. (1989). Molecular cloning a laboratory manual 2ed. Clod spring Harbor laboratory, New York.

Schulman, A. H. (2007). Molecular markers to assess genetic diversity. Euphytica 158: 313-321.

Shibing, Y. Lu, X., Ye, R., Li, Y., Zhou, Y., Yue, P., Zhao, J., Zhang, C. and Peng, M. (2010). Genetic diversity and population structure in Meconopsis quintuplinervia (Papaveraceae). African Journal of Biotechnology 9 (21): 3048-3053.

Siahsar, B.A., Allahdoo, M. and Shahsevand Hassani, H. (2011). Genetic variation among and within tritipyrum (Thinopyrum bessarabicum $\times$ Triticum durum) lines using PCR-based molecular markers. Cien. Inv. Agr. 38(1): 127-135.

Silva, T.D.J.A., Nhut, D.T., Giang, D.T.T. and Rashid, S.Z. (2005b). Molecular markers assisted phylogeny and breeding in ornamental, physiological model, medicinal and aromatic plants. In: Genetic Resources, Biotechnolgy, (Eds): D. Thangadurai, T. Pullaiah, M.A. Pinheiro de Carvalho. Vol. 111, Regency Publications. New Delhi, India, pp 309-326.

Silva, T.D.J.A., Yonekura, L., Kaganda, J., Mookdasanit, J., Nhut, D.T. and Afach, G. (2005a.) Important secondary metabolites and essential oils of spices within the Anthemidae (Asteraceae). J. Herbs Spices Med. Plants 11: 1-46.

Sofia, S.H., Silva, C.R.M., Galindo, B.A., Almeida, F.S., Sodre, L.M.K., Claudia, B.R.M. (2006). Population genetic structure of Astyanax scabripinis (Teleostei, Characidae) from an urban stream, Hydrobiology 553: 245-254

Souframanien, J. and Gopalakrishna, T. (2004). A comparative analysis of genetic diversity in blackgram genotypes using RAPD and ISSR markers. Theoretical and Applied Genetics 109: 1687-1693.

Sun, G., Bond, M., Nass, H., Martin, R and Dong, Z., (2003). RAPD polymorphisms in spring wheat cultivars and lines with different level of Fusarium resistance. Theor. Appl. Genet. 106: 1059 - 1067.

Van Slageren, M.W. (1994). Wild wheats: a monograph of Aegilops L. and Amblyopyrum (Jaub. and Spach) Eig (Poaceae). Wageningen Agriculture University Papers 1994, vol.7, ICARDA, Aleppo.

Wright, S.(1931). Evolution in Mendelian populations. Genetics 16: 97-159.

Wu, C.J., Cheng, Z.Q., Huang, X.Q., and Yin, S.H. (2004). Genetic diversity among and within population of Oryza Granulate from Yunnan of China revealed by RAPD and ISSR markers: implications for conservation of the endangered species. Plant Sci. 167: 35-42.

Yeh, F.C., Yang, R. and Boyle, T. (1999). POPGENE: Microsoft Windows-based freeware for population genetic analysis. Release 1.31. University of Alberta. Canada. http://www. ualberta.ca/ fyeh/index.htm.

Zaharieva, M., Gaulin, E., Havaux, M., Acevedo, E. and Monneveux, P. (2001). Drought and heat responses in the wild wheat relative Aegilops geniculata Roth: potential interest for wheat improvement. Crop Sci. 41: 1321-1329

Zhu, Y., Chen, H., Fan, J., Wanf, Y., Li, Y., Chen, J., Fan, J., Yang, S., Hu, L., Leung, H., Mew, T.W., Teng, P.S., Wang, Z., Mundt, C.C. (2000). Genetic diversity and disease control in rice. Nature 406: 718- 722. 